\title{
SPATIAL DISTRIBUTION OF LOCAL INITIATIVES IN THE FIELD OF EDUCATION IN POLAND
}

Local initiatives are becoming the subject of study of social geography due to its intention to examine social phenomena and processes on the smallest scale possible. The growth of authentic popular movements aiming at the improvement , of life conditions on the local scale is considered to be the result of the inefficiency of central planning which disregards, to a great extent, the actual needs of local communities.

The development of social initiatives in the areas that used to be the domain of the state, such as education, health care, culture, etc.. is due to the reason stated above, as well as, to the state's precise definition of its financial potential. While the increase of expenses to meet social needs is officially voiced, the underlying tone is that of the appeal to the society itself whose financial help is indispensable for the recovery from the fatal effects of the lack of concern for these matters during the period of intensified industrialisation and consummerism of the $70^{\prime} \mathrm{s}$. Due to the unavailability of the results of studies in this field, it is hard to assess which of the above reasons for the present animation of social initiatives emerges as the predominant factor and to estabilish their spatial distribution. The purpose of the present paper is to estabilish a set of problems for geographic study of the forthcoming social initiatives in the field of education. The available statistical data will support the attempt at presentation of regional distribution of educational initiatives and their intensity; they will also help to correlate the initiatives in question with other possible determining factors.

\section{DEFINITION OF LOCAL INITIATIVE}

Although the Latin initiatio has several equivalents such as impulse to action, ingenuity, originality, enterprise, introduction of proposals, the literal translation of the word does not determine the "initiator" of the actions. In the analysis of local initiatives it is essential to establish the degree of their authenticity i.e. to what extent they ar the effect of 
the decision of a particular community, and in what degree they are "created" by the administration, even the most efficient one. There are two types of local initiatives: of genuine grass-roots nature, and centrally controlled ones. To give an example of the first type one can cite Buergerinitiativen in the German language areas of Western Europe, which function on the level communities but frequently, due to the importance of their issues (especially recent ecological concerns) they expand and function on the national scale. The controlled initiatives, on the other hand, as for instance in Poland, originate from a central decision-making institution and their place is determined by various political factors.

Recent local initiatives in Poland are, to a great extent, authentic although they have been launched by official political sources. Therefore we may approach the problem of Polish local initiatives from three points of view:

(1) socio-geographic: local initiative being an articulation of the need of a community for a project meeting local wants;

(2) economic: the project being financed from the funds of the community or with the support from the outside;

(3) structural: local initiatives may be aimed at a single aspect of social life or it may be of complex nature.

One can distinguish two types of causal factors as regards local initiatives: (1) primary starting factors: absence or decapilization infrastructure; (2) cooperative factors: availability of local leadership, local tradition of grass-roots activity, stimulating example from the neighbourhood.

The above list is not complete. Other factors can be distinguished in the course of further research. The present pilot studies show that the most important factor for educational initiatives is the appearance of local leadership, whereas the emergence of such leadership seems to be directly related to the existence of local tradition of grass-roots activities.

\section{EDUCATIONAL INITIATIVES IN POLAND}

The present grass-roots movement in support of education (National School Aid) initiated in December, 1984 differs from former initatives in its scope and ways of financing. Former movements (in the years 1947-1956, 1958-1965, and 1966-1972) were concerned mainly with the establishment or modernization of educational premises and were financed from taxes which were levied on the whole working population, individual farmers, and private enterprises. The present initiatives have all the characteristics of a grass-roots movement in spite of the fact that they have been launched by central institutions. The central management of the initiatives consists of gathering and passing on information as well as in collecting and re-distribution of voluntary donations paid 
to a central account. However, the means for the implementation of local initiatives are collected mainly within communities: as individual donations or contributions from the profits of local enterprises. Such a handling of the movement enhances its authenticity and independence from central management. On the other hand, the activities of the present movement go beyond material concerns by initiating campaigns aiming at interaction between schools and communities.

Social participation in the development of education in Poland is quite considerable. In the past 2484 (i.e. $40 \%$ of the total number) school complexes were built with the funds from public contributions. At present there are 3867 (December, 1986) committees for the construction, enlargement and modernization of educational premises, which considerably exceeds the respective potential of the state.

\section{EDUCATIONAL INITIATIVES AND SPATIAL PLANNING}

Studies of spatial distribution of educational initiatives provide answers to two essential questions. First of all, to what extent educational initiatives indicate actual public needs as regards education. Secondly, to what extent the appearance of educational initiatives reflects the general public involvement. What is more, both questions are of utmost importance for spatial-social planning and social engineering. The guidelines for the location of school buildings provided by the state are so general and non-specific that if implemented directly i.e. without checking particular circumstances of given localities, might end in abortive projects. That was a common practice in the past; frequently the site and the size of school premises did not correspond to actual needs. Moreover, the distribution of the density of these initiatives was determined partly by geo-political reasons, i.e. the policy of efficient management of territories recovered after World War II.

Present educational initiatives should emerge, first of all, in localities where schools are unavailable, i.e. in places where residents themselves consider a new educational facility necessary. From the viewpoint of spatial management the most advantageous situation results from the correlation of the requirements of spatial planning with local initiatives. In fact, there is usually a mutual agreement on the part of authorities and the community as regards the opening or modernization of a school building. However, negotiations involve the distribution of expenses between the community and the state as well as the type of a newly estabilished school unit. At this point one should emphasize the fact that in financing educational initiatives an important role is played both funding of the initiatives as well as large plants whose taxes supplement local budgets and are subsequently distributed, with some participation of residents, for social needs. 


\section{SPATIAL DISTRIBUTION OF EDUCATIONAL INITIATIVES IN POLAND}

The number of residents corresponding to one educational initiative in a given voivodship has been assumed as an index of density of educational initiatives. Spatial distribution of this index has been presented in Figure 1. Earlier research suggested the correlation of the index of density of educational initiatives with the following indices by means of Spearman rank correlation coefficient:

- the degree of urbanization (percentage of residents of rural areas).

- population density.

- the degree of industrialization (percentage of population employed in industry). schools).

- availability of schools (percertage of rural settlements with no

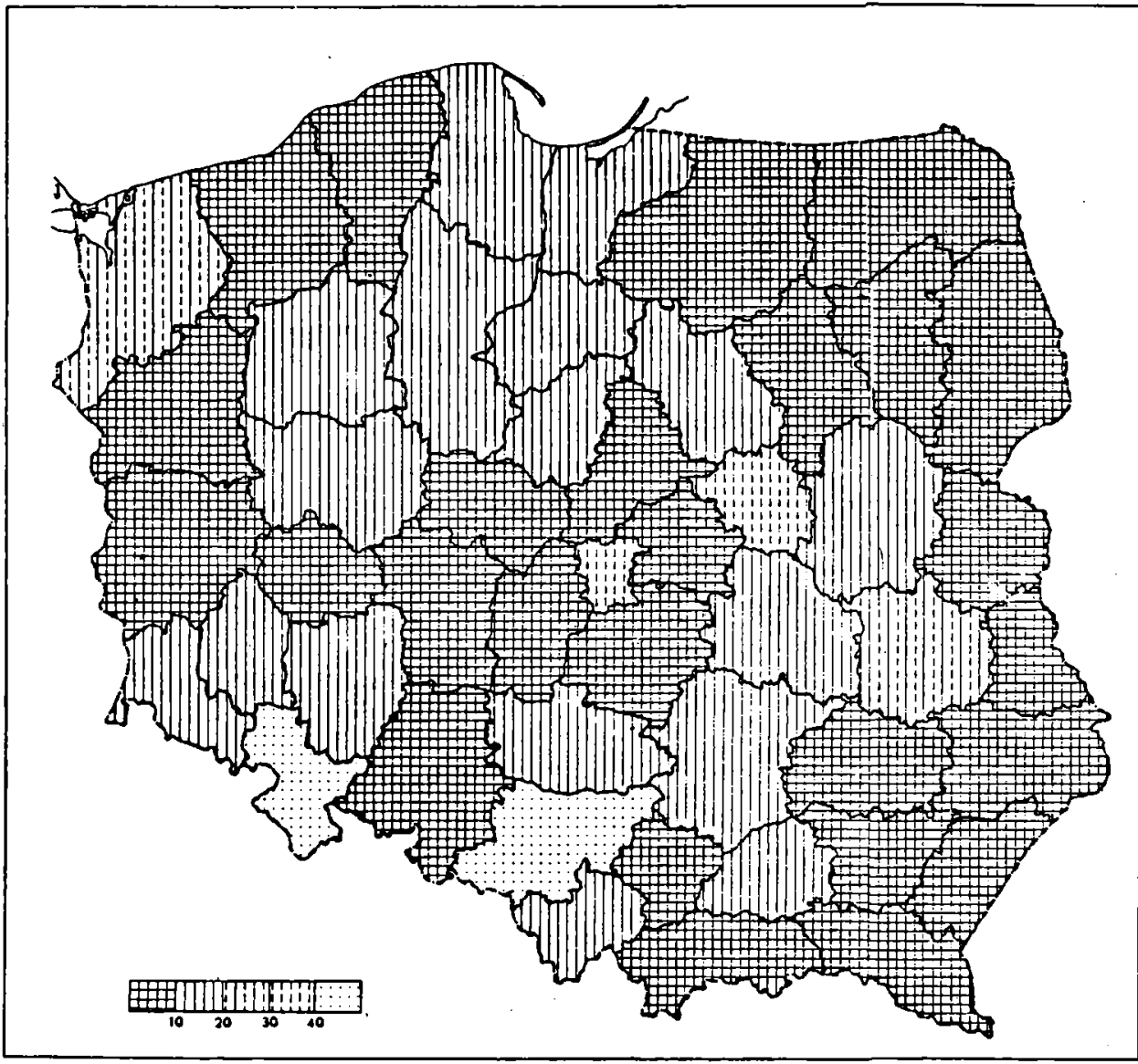

Fig. 1. The density of educational initiatives resistents in thousand per one initiative 
The above sequence reflects the respective values of correlation coefficient: $0.63,0.50,0.23-0.03$. The lack of correlation between the density of educational initiatives and the availability of schools does not suggest the absence of any actual relation between the two features. It is rather indicative of the fact that the interrelationship exists on the local scale. It also supports the earlier assumption of the author of the present paper as regards the local nature of availability of means of satisfaction of social needs. Other values of the coefficient indicate that the highest density of educational initiatives appears in poorly urbanized and underpopulated areas which, in fact, lack educational facilities. Moreover, the correlation between the density of initiatives and the degree of industrialalization seems to be of no statistical consequence which, again, points to the need of its re-examination on a local scale. Figure 2 shows the spatial distribution of the financial structure of educational activities.

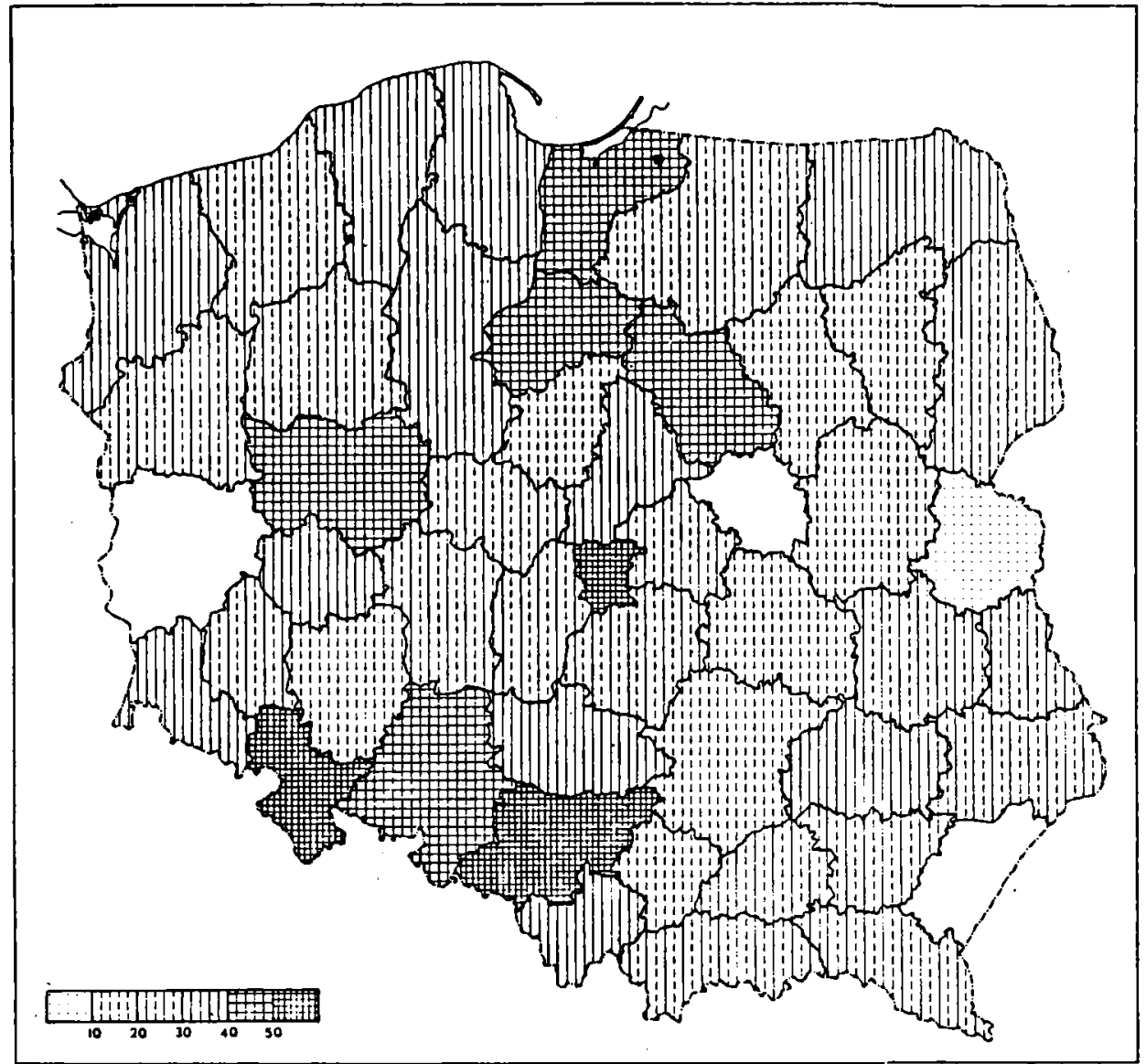

Fig. 2. The contribution of residents to educational initiatives in per cent 
Comparing the cartogram in Figure 2 with the Figure 1, one can observe only two distinet types of correlations.

(1) In voivodships with high density of educational initiatives there is negligible participation of residents in the implementation of these initiatives; these voivodships are chielfy rural: Biała Podlaska, Łomża, Ostrołęka, Siedlce, Włocławek.

(2) In voivodships with low density of initiatives there is a considerable participation of the population in the financing of educational projects; these voivodships are highly industrialized (Katowice, Wałbrzych, Łódź). Therefore, it may turn out that the participation of residents in financing of educational initiatives depends simply on their income.

Figure 3 presents the distinction between urban and rural areas being taken into account. This cartogram supplements cartogram in Figure 1 and supports an earlier thesis that a considerable majority of educational initiatives arise in rural areas. Therefore, these areas in particular deserve

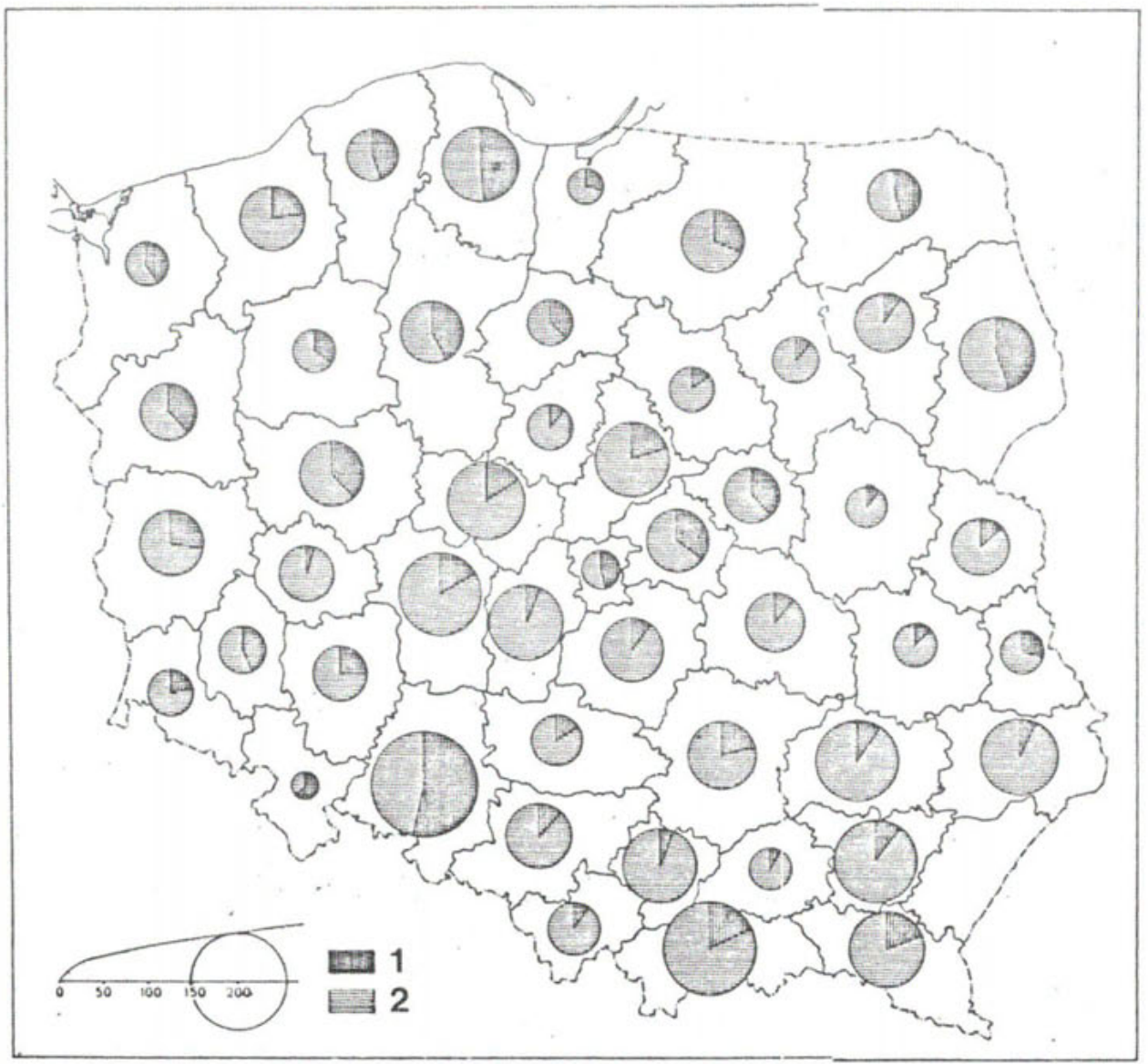

Fig. 3. The territorial structure of educational initiatives 1. in towns, 2 . in rural areas 
a thorough examination with respect to the reasons and socio-spatial correlations of educational initiatives. The work on an appropriate questionnaire is hampered by the lack of precise data for some voivodships. This is also rendered on the cartograms. The present movement is free from the obligation to report its activities to the centre, which also proves its local and grass-roots character.

\section{EDUCATIONAL INITIATIVES VERSUS OTHER SOCIAL INITIATIVES}

One of the features of social participation is its variety. Therefore, one may assume that educational initiatives accompany other initiatives aiming at the satisfaction of different social needs. Active social movement for the enlargement modernization of infrastructure appears also in the field of health care, culture, religious life. It seems essential to examine spatial distribution of social involvement (i.e. social initiatives in these spheres of life) as it may help in the delineation of regions of social landscape in Poland. The analysis of available statistical data tentatively supports the hypothesis as to the regional differences in the level of social involvement and as to the variety of social initiatives. Confirmation of these hypotheses appears to be a further if not the final aim of the proposed field-work.

\section{REFERENCES}

Architektura i budownictwo szkolne PRL, 1976 (Architecture and school building in People's Polish Republic), Warszawa, pp. 15-36.

Informacja o Narodowym Czynie Pomocy Szkole (Note on National School Aid) published by the Committete of National School Aid, Warszawa 1987, stensil p. 12.

R a jkiewicz, A., 1988, „The State of the social infrastructure in social geography”, in $\dot{Z}$ Otok, S. (ed.) Research Approach to Social Geography, Departament of Geography and Regional Studies, University of Warsaw, Warszawa.

R y ki e l, Z., „Koncepcja geografii spolecznej a badania Polski lokalnej” (Concept of Social Geography and the Study of Local Poland), CPBP archives 09.8, Warszawa 1986, typescript, pp. 25. 
